\title{
Sifat Mekanis Polipropilena Berpenguat Serat Kenaf Pendek: Pengaruh Fraksi Massa dan Talk
}

\author{
Erfina Oktariani ${ }^{*}$, Rochmi Widjajanti, Syaiful Ahsan, Recky Pahlevi A.P., Faisal Amir, \\ Lidia Jane Heryes, Ayu Wulandar ${ }^{1}$ \\ *e-mail: erfina@kemenperin.go.id
}

\author{
Program Studi Teknik Kimia Polimer, Politeknik STMI Jakarta, Kementerian \\ Perindustrian R.I.
}

\begin{abstract}
There have been few studies in the development of natural fibers reinforced thermoplastic as composite materials for the small size components in the automotive industries. The complexity level and failure potential at composite manufacturing are main reasons for slightly development. The objective of this study is to find the best composition of Polypropylene/Kenaf fibers (PP/Kenaf) with optimal tensile and flexural strength as an alternative material for small size component in the automotive industries. Sandwich methods of PP/Kenaf composites using hot press machine are selected. Short kenaf fiber $(5 \mathrm{~mm})$ are employed in this study. Mass fraction of kenaf in the composite and talc are investigated in order to find their effects to the tensile and flexural strengths of PP/Kenaf composite. Results show that the best composition is $30 \%$ (wt) Kenaf due to its optimal tensile and flexural strength as material for smallsize components in the automotive industries.
\end{abstract}

Keywords: kenaf, short fiber, polypropylene, tensile strength, flexural strength

\begin{abstract}
ABSTRAK
Sampai saat ini masih jarang dijumpai penelitian yang mengembangkan material komposit termoplastik-serat alam sebagai bahan baku komponen berukuran kecil di industri otomotif. Hal ini dikarenakan tingkat kerumitan dan kemungkinan gagal (failure) saat pencetakan komposit tersebut. Tujuan penelitian ini adalah untuk mendapatkan komposisi terbaik Polipropilena-serat Kenaf (PP/Kenaf) dengan nilai kekuatan tarik dan lentur yang optimal sebagai bahan baku alternatif komponen berukuran kecil di industri-industri otomotif. Metode yang dipakai adalah membuat sandwich komposit PP/Kenaf dengan menggunakan mesin hot press. Kenaf serat pendek $(5 \mathrm{~mm})$ digunakan dalam penelitian ini. Variasi fraksi massa kenaf dalam komposit serta keberadaan talc dilakukan untuk mengamati pengaruhnya terhadap kekuatan tarik dan lentur PP/Kenaf. Hasil penelitian menunjukkan bahwa komposisi Kenaf yang paling baik adalah $30 \%$ Kenaf tanpa talk karena memiliki sifat mekanis yang cukup kuat dan lentur sebagai salah satu komponen mobil yang berukuran kecil.
\end{abstract}

Kata Kunci: kenaf, serat pendek, polipropilena, kekuatan tarik, kekuatan lentur

\section{PENDAHULUAN}

Ketertarikan industri otomotif pada serat-serat alam sebagai pengganti serat kaca (fiber glass) pada material termoplastik berpenguat untuk komponen-komponen otomotif terus meningkat (Mohanty, 2004). Lebih jauh 
lagi, serat-serat alam memiliki lebih banyak keuntungan daripada serat sintetis dilihat dari keterbaruannya, lebih ekoefisien dan berat produk yang lebih ringan (Husin, 2017). Serat Kenaf memiliki potensi yang lebih besar untuk dikembangkan daripada semua jenis serat tanaman lainnya karena sifat-sifat mekanisnya.

Manufaktur komposit serat alam merupakan penggunaan sistem binder dari polimer termoset ataupun termoplastik yang dikombinasikan dengan jalinan serat alam yang siap pakai. Sistem yang paling umum diterapkan di otomotif adalah termoplastik polipropilena, khususnya untuk komponen non-struktural. Polipropilena disukai karena densitas yang rendah, dapat diproses dengan mudah, sifat mekanis, sifat elektrik yang sempurna serta stabilitas dimensi dan kekuatan tumbukan yang baik. Meskipun demikian, beberapa termoplastik sintetis juga digunakan termasuk polietilena, polistirena dan poliamida (Holbery, 2006).

Pengembangan

komposit termoplastik serat-alam dibatasi oleh dua batasan fisik utama yaitu batas atas temperatur serat dapat diproses serta perbedaan yang signifikan antara energi permukaaan kayu dan matriks polimer. Temperatur proses merupakan faktor pembatas dalam penerapan serat alam. Secara umum, batas atas temperatur diartikan sebagai temperatur sebelum serat mulai terurai (terdegradasi) yaitu pada $150^{\circ} \mathrm{C}$ untuk proses dengan durasi yang lama. Meskipun demikian, serat dapat bertahan pada proses dengan durasi pendek sampai dengan $220^{\circ} \mathrm{C}$ (Holbery, 2006).

Honda sebagai salah satu perusahaan besar industri otomotif di dunia, telah menggunakan material komposit serat alam di bagian lantai (floor) mobil Sport Utility Vehicle (SUV). Serat alam yang digunakan adalah serbuk kayu. Di lain pihak, BMW Group akan mempertimbangkan penggunaan serat alam campuran antara kenaf dan kain linen sebagai penguat di door panel Saturn L 300S. Beberapa industri otomotif lainnya di Amerika juga sudah menggunakan komposit serat alam di komponen-komponen besar bagian mobil seperti pintu, alas/ lantai, isian pintu sliding, dan sebagainya. Toyota memiliki ketertarikan untuk menggunakan kenaf sebagai campuran komposit di struktur badan mobil (Holbery, 2006). Pengembangan komposit plastik serat alam untuk pembuatan bumper terus diteliti (Jeyanthi, 2014).

Sampai saat ini penggunaan komposit serat alam di industri otomotif belum menjangkau komponen-komponen berukuran kecil. Hal ini dikarenakan tingkat kerumitan dan kemungkinan gagal (failure) saat pencetakan komposit tersebut. Komponen mobil berukuran kecil seperti door handle and lock, cover kaca spion, dan lain-lain masih menggunakan komposit termoplastik dengan serat dan aditif sintetis. Selain itu juga masih dijumpai kekhawatiran akan rendahnya kekuatan komposit jika menggunakan serat alam berukuran pendek $(<1 \mathrm{~cm})$.

Penelitian ini bermaksud mengembangkan penggunaan serat Kenaf berukuran pendek $(5 \mathrm{~mm})$ sebagai penguat dalam komposit Polipropilena agar dapat dipakai menjadi bahan baku komponen berukuran kecil di industriindustri otomotif khususnya mobil. Tujuan dari penelitian ini adalah untuk mendapatkan komposisi terbaik Polipropilena-serat Kenaf (PP/Kenaf) dengan nilai kekuatan tarik dan lentur yang optimal sebagai bahan baku alternatif komponen berukuran kecil di industri-industri otomotif. 


\section{METODE PENELITIAN}

Penelitian ini dilakukan secara eksperimental di Politeknik STMI Jakarta, Kementerian Perindustrian yang terdiri dari empat tahapan yaitu persiapan bahan, pembuatan komposit PP/Kenaf, pembuatan spesimen dan pengujian kekuatan tarik dan lentur.

\section{PERSIAPAN BAHAN}

Serat kenaf diperoleh dari PT GAN (Global Agrotek Nusantara), Karangploso, Malang, Jawa Timur. Dalam rangka untuk meningkatkan pembentukan ikatan antarmuka (interface) yang baik antara serat kenaf dan matrik polipropilena maka serat kenaf direndam dalam larutan alkali $(\mathrm{NaOH} 6 \%, 24$ jam) untuk proses delignifikasi. Setelah proses perendaman selesai kemudian serat kenaf, dicuci dengan air bersih yang mengalir sampai hilang alkalinitas-nya atau sampai air bilasan bersifat netral. Setelah proses pencucian, serat dijemur dibawah sinar matahari sampai kering atau berat konstan. Kemudian serat kenaf dipotongpotong pendek (chopped) secara manual dengan alat pemotong kertas/gunting dengan ukuran panjang serat $5 \mathrm{~mm}$. Proses alkali ini bertujuan untuk proses delignifikasi atau akan melarutkan senyawa amorph seperti hemiselulosa, wax dan lignin. Proses alkali dapat meningkatkan kekasaran permukaan serat sehingga dapat terbentuknya mekanisme perekatan ikatan antarmuka (interface) serat dan matriks pada susunan komposit.

Resin PP yang digunakan dalam penelitian ini adalah Homopolymer Polypropylene Injection Grade MAS 5402 dari PT. Polytama Propindo. Resin tipe injection dipilih karena menyesuaikan proses pencetakan prototipe yang menggunakan mesin jenis injection molding. PP-g-MA yang dipakai berasal dari China dengan merk All Gong. Antioksidan yang digunakan adalah Irganox tipe primer dan sekunder.

\section{PEMBUATAN KOMPOSIT}

\section{$\mathrm{PP} / \mathrm{KENAF}$}

Mesin ekstruder digunakan dalam pembuatan lembaran plastik PP pada penelitian ini. Tipe ekstruder yang digunakan adalah Collin E $30 \mathrm{M}$, tipe single screw Pada ujung keluaran/die ekstruder disambungkan dengan alat callendering (chillroll) untuk menjadikan lelehan polipropilen menjadi bentuk lembaran-lembaran. Kecepatan putar screw diatur pada putaran (n1) $90 \mathrm{rpm}$ sebagaimana terlihat pada Gambar 1.

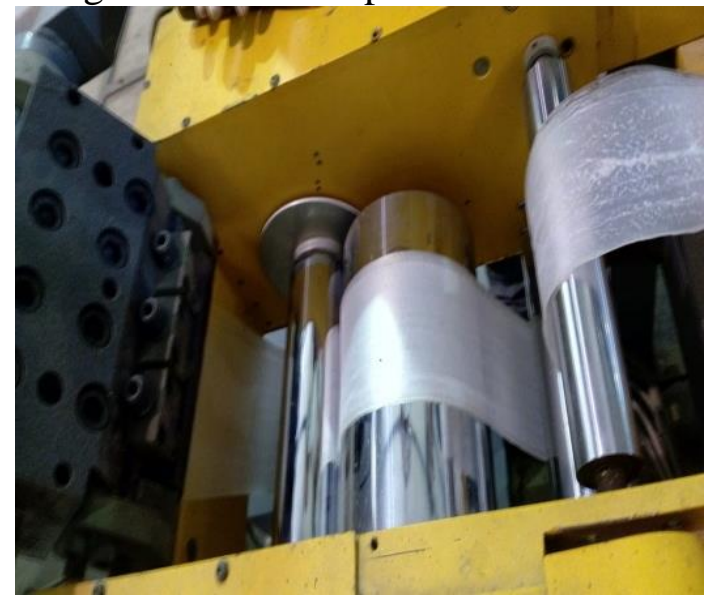

Gambar 1. Pembuatan lembaran polipropilena dengan mesin callendering

Sebelum dimasukkan ke dalam ekstruder, polypropylene graft maleic anhydride (PP-g-MA) dicampur dengan resin PP sebesar 5\% dari berat total resin polipropilen yang akan dibuat menjadi lembaran. PP-g-MA berfungsi sebagai bahan pembantu atau Coupling Agent untuk memberikan gugus hidrofilik yang dapat berikatan dengan serat alam sedangkan gugus polimer dapat bertautan dengan matrik polimer sehingga terbentuk ikatan antara serat dan matrik.

Fraksi massa serat Kenaf bervariasi pada 10, 20 dan 30\% dari total massa komposit PP/Kenaf. Selain itu juga diamati pengaruh keberadaan talk sebagai pengisi dalam komposit PP/Kenaf dengan menambahkan talk sebesar $0,8 \%$.

\section{PEMBUATAN SPESIMEN}


Proses yang dipilih untuk membuat material komposit Kenaf-PP adalah proses hot press. Serat Kenaf dan lembaran PP yang telah dipotong sesuai ukuran cetakan kemudian disusun bersama serat Kenaf menjadi lapisanlapisan kemudian diletakkan di dalam mesin hot press. Mesin Hot Press yang digunakan adalah merk Collin tipe P 300 $\mathrm{P}$ dengan tekanan maksimun $300 \mathrm{kN}$ dan kapasitas panas $2 \times 11.6 \mathrm{~kW}$.

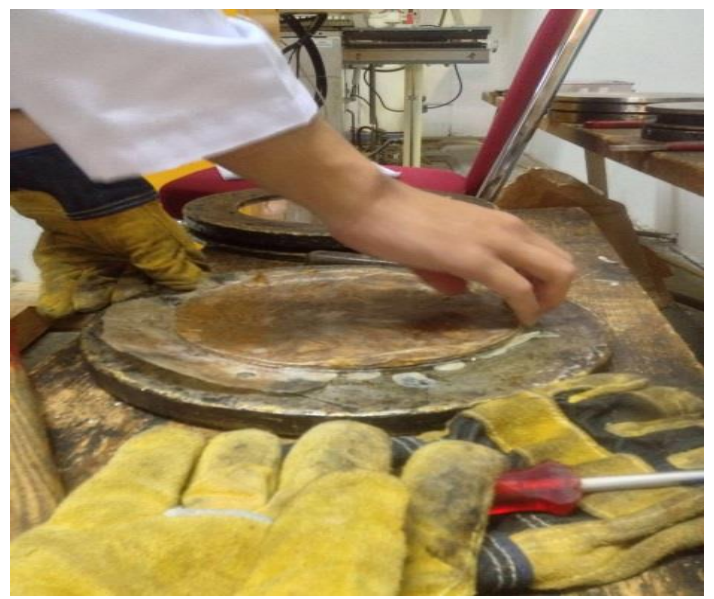

Gambar 2. Pembuatan lapisan komposit $\mathrm{PP} /$ Kenaf

Jumlah lapisan Kenaf dan lembaran polipropilen disusun dengan 3 lapisan (ply). Setelah lapisan tersusun rapi, kemudian diletakkan pada cetakan logam, diberi tekanan sebesar 50 bar, dipanaskan pada temperatur $210^{\circ} \mathrm{C}$ selama 5 menit (Gambar 2). Lapisan berupa lembaran tersebut kemudian dikeringkan kembali di dalam oven pada temperatur $80^{\circ} \mathrm{C}$ selama 2 jam sebelum dilakukan pencetakan spesimen.

4. PENGUJIAN KEKUATAN TARIK DAN LENTUR

Kekuatan tarik komposit diuji berdasarkan standar ASTM D638.Spesimen pengujian mengikuti alat pencetak spesimen tipe IV dengan panjang dimensi $75 \mathrm{~mm}$, lebar $6 \mathrm{~mm}$ seperti pada. Pengujian dilakukan dengan menggunakan alat universal testing machine SHIMADZU tipe AGS-10kNG dengan kecepatan pengujian sebesar 5 $\mathrm{mm} / \mathrm{min}$, panjang gripped sebesar $65 \mathrm{~mm}$ dan pretension 0,5 Mpa. Spesimen dibuat dengan menggunakan alat cetak atau punchure untuk pengujian kekuatan tarik, kemudian ditekan menggunakan alat minitest press. Banyaknya spesimen yang diuji ada 5 untuk memperoleh nilai ratarata dari kekuatan tarik.

Pengujian kekuatan lentur yang dilakukan mengacu pada standar ASTM D790 menggunakan three point bending. Ketebalan spesimen $2 \mathrm{~mm}$ dengan panjang spesimen minimal 16 kali ketebalan spesimen ditambah dengan 10 $\%$ support span pada tiap ujung-ujung spesimen. Pengujian dilakukan dengan menggunakan alat universal testing machine SHIMADZU tipe AG-X plus dengan tipe pengujian tiga titik lentur (three point bend). Kecepatan pengujian disesuaikan terhadap ketebalan spesimen yang akan diuji. Banyaknya spesimen yang diuji ada 5 untuk memperoleh nilai rata-rata dari kekuatan lentur. Bentuk Spesimen Pengujian Kekuatan Lentur dapat dilihat pada Gambar 3.2 Spesimen dibuat secara manual dengan ukuran tebal dan panjang sesuai standar ASTM D 790 kemudian dipotong-potong menggunakan mesin gerinda.

\section{HASIL DAN PEMBAHASAN}

Berat Kenaf menyusut $16,7 \%$ setelah mengalami perlakuan alkali. Hal ini dikarenakan lignin sudah terlarut dalam larutan alkali. Persentase penyusutan ini telah membuktikan literatur yang menyebutkan kadar lignin dalam serat kenaf berkisar $15-17 \%$ (Asumani, 2012).

\section{Pengaruh Fraksi Massa Kenaf dan Keberadaan Talk terhadap Kekuatan Tarik (Tensile Strength) Komposit PP/Kenaf}

Kekuatan tarik adalah salah satu sifat dasar dari suatu bahan. Material yang digunakan untuk front \& rear bar 
sampai saat ini adalah Acrylonitrile butadiene styrene (ABS). Kekuatan tarik front \& rear bar untuk mobil jenis MPV di pasaran adalah 25-35 Mpa. Tabel 1 memperlihatkan nilai rata-rata hasil pengujian kekuatan tarik dari 6 (enam) macam variasi kompon $\mathrm{PP} /$ Kenaf serat pendek.

Tabel 1. Hasil Pengujian Kekuatan Tarik

\begin{tabular}{|l|l|l|c|}
\hline No & $\begin{array}{l}\text { Kenaf } \\
(\%)\end{array}$ & $\begin{array}{l}\text { Talc } \\
(\%)\end{array}$ & $\begin{array}{c}\text { Kuat Tarik } \\
(\mathrm{Mpa})\end{array}$ \\
\hline 1. & 10 & 0 & 26,15 \\
\hline 2. & 20 & 0 & 27,44 \\
\hline 3. & 30 & 0 & 28,41 \\
\hline 4. & 10 & 0,8 & 25,14 \\
\hline 5. & 20 & 0,8 & 26,15 \\
\hline 6. & 30 & 0,8 & 27,26 \\
\hline
\end{tabular}

Tabel 1 menunjukkan nilai kekuatan tarik komposit dari setiap masing-masing variasi. Nilai kekuatan tarik yang dihasilkan adalah nilai ratarata dari 5 spesimen yang diuji dengan deviasi $\pm 1,04$. Hasil pengujian kekuatan tarik menunjukkan jika front \& rear bar dari kompon PP/Kenaf serat pendek dapat menjadi pilihan karena masih masuk kategori dari front \& rear bar konvensional. Keberadaan talc dalam hal ini $\mathrm{CaCO}_{3}$ ternyata tidak memberikan pengaruh yang signifikan terhadap nilai kekuatan tarik prototipe dari komposit $\mathrm{PP} /$ Kenaf serat pendek.

\section{Pengaruh Fraksi Massa Kenaf dan Keberadaan Talk terhadap Kekuatan Lentur (Flexural Strength)}

Kekuatan lentur suatu material dapat diketahui dengan melakukan pengujian dengan uji bending atau flexural terhadap material komposit tersebut Pengujian ini dimaksudkan untuk mengetahui keelastisan suatu bahan dengan pemberian beban tertentu. Akibat pengujian bending bagian atas spesimen mengalami tekanan, sedangkan bagian bawah akan mengalami tegangan tarik. Tabel 2 menunjukkan nilai kekuatan lentur komposit dari setiap masing-masing variasi. Nilai kekuatan lentur yang dihasilkan merupakan nilai rata-rata dari 5 spesimen yang diuji.

Tabel 2. Hasil Pengujian Kekuatan Lentur

\begin{tabular}{|l|l|l|c|}
\hline No & $\begin{array}{c}\text { Kenaf } \\
(\%)\end{array}$ & $\begin{array}{c}\text { Talc } \\
(\%)\end{array}$ & $\begin{array}{c}\text { Kuat Tarik } \\
(\mathrm{Mpa})\end{array}$ \\
\hline 1. & 10 & 0 & 60,36 \\
\hline 2. & 20 & 0 & 62,42 \\
\hline 3. & 30 & 0 & 63,91 \\
\hline 4. & 10 & 0,8 & 55,62 \\
\hline 5. & 20 & 0,8 & 61,16 \\
\hline 6. & 30 & 0,8 & 61,55 \\
\hline
\end{tabular}

Nilai kekuatan tarik dan kekuatan lentur pada komposit PP/Kenaf berukuran pendek ini lebih rendah dibandingkan dengan penelitian sebelumnya yang telah menggunakan serat Kenaf berukuran panjang $5 \mathrm{~cm}$ (Oktariani, 2018). Hasil ini sesuai dengan pernyataan Mohanty pada tahun 2004 bahwa ukuran serat yang pendek dapat mengurangi sifat kekuatan tarik material. Tetapi, nilai kekuatan tarik dan kekuatan lentur komposit PP/Kenaf pendek ini sudah dapat memenuhi standar bahan baku komponen-komponen berukuran kecil di industri otomotif.

\section{KESIMPULAN}

Dari hasil dan pembahasan diperoleh kesimpulan bahwa komposisi komposit polipropilena-serat kenaf yang paling baik adalah 30\% Kenaf tanpa penambahan talc $0,8 \%$ karena memiliki sifat mekanis kekuatan tarik yang cukup tinggi dan lentur sebagai salah satu komponen mobil yang berukuran kecil (small-size body work parts).

\section{Ucapan Terimakasih}

Penelitian ini sepenuhnya dibiayai oleh Sarana Penelitian Industri Terapan (SPIRIT) dari Pusdiklat Industri Kementerian Perindustrian Tahun Anggaran 2017. 


\section{DAFTAR PUSTAKA}

Asumani, OML, Reid, RG \& Paskaramoorthy, R. (2012). The effects of alkalisilane treatment on the tensile and flexural properties of short fiber nonwoven kenaf reinforced polypropylene composites, Composites Part A:Applied Science and Manufacturing, 43, 1431-1440.

Holbery J dan Houston D. (2006). Natural-Fiber-Reinforced Polymer Composites in Automotive Applications, Journal of the Minerals, Metals and Materials Society, 58(11), 80-86.

Husin, M.M., Mohammad Sukri Mustapa, Md Saidin Wahab, Ahmad Mubarak Tajul Arifin, Reventheran a/l Ganasan, Farhana Hazwanee Jais. (2017). Characteristics on Treated Kenaf Fiber Reinforced Polypropylene Composites, Materials Science Forum 909, 94-99.

Jeyanthi, S. and J.J. Rani. (2014). Development of natural long fiber thermoplastic composites for automotive frontal beams, Indian Journal of Engineering \& Materials Sciences, 21, 580-584.

Mohanty, AK, A., Wibowo, M. Misra \& Drzal, LT. (2004). Effect of process engineering on the performance of natural fiber reinforced cellulose acetate biocomposites, Composites Part A: Applied Science and Manufacturing, 35, 363-70.

Oktariani, E., Rita Istikowati, Hendro Sat Setijo Tomo, Rafliansyah Rizal, Yosea Pratama. (2018). Multi response optimization of sheet forming of Kenaf-Polypropylene composites using grey based fuzzy algorithm, AIP 